Langi, et al/JurnalEkonomi Syariah Teori dan Terapan Vol. 6 No. 1 Januari 2019: Hal 188-197; MANAJEMEN RISIKO PEMBIAYAAN MUSYARAKAH MUTANAQISAH DI BANK MUAMALAT INDONESIA KC MAS MANSYUR SURABAYA

\title{
MANAJEMEN RISIKO PEMBIAYAAN MUSYARAKAH MUTANAQISAH DI BANK MUAMALAT INDONESIA KC MAS MANSYUR SURABAYA
}

\author{
Gea Papurane Langi \\ Departemen Ekonomi Syariah-Fakultas Ekonomi dan Bisnis-Universitas Airlangga \\ Email: gea.langi@yahoo.com \\ Imron Mawardi \\ Departemen Ekonomi Syariah-Fakultas Ekonomi dan Bisnis-Universitas Airlangga \\ Email: ronmawardi@yahoo.co.id
}

\begin{abstract}
:
This research is done to see any risks that happened in Islamic bank, which can damage the bank. While it aims to find out the strategy used by Bank Muamalat Indonesia (BMI) to reduce the risk faced and often happened in the field. The research method uses a qualitative approach with a case study method. Data collecting was done by relating proposed questions and the conclusion made from the result of the interview with Branch Manager (BM), Relation Manager, and Remedial BMI of Branch Office of Mas Mansyur. The result of this research showed that BMl of Mas Mansyur Branch Office had done the process of risk management by identifying risk in the manner of finding out the existing risks which are financing risk; market risk; and ownership risk, measuring and monitoring the risks in the manner of doing measurement to find out and see any reason that causes those risks exist, and controlling and managing the existing risks in Musyarakah Mutanaqisah (MMQ) financing in the manner of ways that have already determined by BMl of Mas Mansyur Branch Office. The last is by monitoring the risks in MMQ financing at BMI of Mas Mansyur Branch Office.

Key Words: Risk Management, Risk, Financing, Musyarakah Mutanaqisah, Bank Muamalat Indonesia
\end{abstract}

\section{PENDAHULUAN}

Perekonomian semakin

berkembang pesat, sehingga kebutuhan akan transaksi ekonomi pada perbankan dari tahun ke tahun meningkat. Salah satu perkembangan bank adalah perbankan Islam. Pengembangan produk bank syariah dibagi menjadi tiga,yaitu: produk penyalur dana, produk penghimpunan dana, dan produk jasa. Produk perbankan yang termasuk ke dalam kelompok bagi hasil adalah musyarakah dan mudharabah. Musyarakah adalah akad kerjasama antara dua pihak atau lebih untuk memberikan kontribusi dana latau amal/expertise) dengan kesepakatan bahwa keuntungan dan risiko akan ditanggung bersama sesuai dengan kesepakatan (Naf'an, 2014:95).

Musyarakah mutanaqisah adalah salah satu solusi pembiayaan bagi nasabah yang membutuhkan suatu barang namum belum memiliki dana yang cukup, bahkan untuk membeli secara mengangsurpun tabungannya belum cukup untuk membayar uang mukanya. Struktur produk berbasis akad dibuat secara multiakad (hybrid) yang selain akad musyarakah terdiri atas akad ijarah (leasing), ijarah mawsufah fi zimmah (advance/forward lease), bai al musawamah (penjualan) ataupun akad istisna (manufaktur). (Standar Produk

1) Jurnal ini merupakan bagian dari skripsi Gea Papurane Langi, NIM: 041411433022, yang telah diuji pada tanggal 17 Januari 2018. 
Langi, et al/JurnalEkonomi Syariah Teori dan Terapan Vol. 6 No. 1 Januari 2019: Hal 188-197; MANAJEMEN RISIKO PEMBIAYAAN MUSYARAKAH MUTANAQISAH DI BANK MUAMALAT INDONESIA KC MAS MANSYUR SURABAYA

Perbankan Syariah Musyarakah dan Musyarakah Mutanaqisah, 2016:114).

Salah satu bank syariah yang menggunakan akad Musyarakah mutanaqisah adalah Bank Muamalat Indonesia. Dalam pembiayaan kemitraan berbasis bagi hasil akad Musyarakah mutanaqisah (MMQ) akan selalu berhadapan dengan berbagai jenis risiko dengan tingkat kesulitan yang beragam. Maka dari itu lembaga keuangan syariah (bank maupun non- bank) juga memerlukan serangkaian prosedur dan metedologi yang dapat digunakan untuk mengidentifikasi, mengukur, memantau, dan mengendalikan risiko yang timbul dari kegiatan usaha, atau yang biasa disebut dengan manajemen risiko ( Karim, 2014:255).

\section{LANDASAN TEORI}

\section{Pembiayaan Syariah}

Definisi

pembiayaan

berdasarkan prinsip syariah adalah penyediaan uang atau tagihan atau yang dapat dipersamakan dengan itu berdasarkan persetujuan atau kesepakatan pinjam meminjam antara bank dengan pihak lain yang mewajibkan pihak peminjam untuk melunasi hutangnya setelah jangka waktu tertentu dengan pemberian sejumlah imbalan atau bagi hasil. Dalam aktivitasnya, pembiayaan tersebut akan dituangkan dengan sim yang sesuai dengan kegiatan yang diperlukan, seprti kontrak murabahah, mudharabah, musyarakah, dan lain-lain.

Pembiayaan Musyarakah
Sesuai Fatwa Dewan Syariah Nasional No. 08/DSN-MUI/VI/2000 tentang pembiayaan musyarakah disebutkan bahwa pembiayaan musyarakah yaitu pembiayaan berdasarkan akad kerjasama antara dua pihak atau lebih untuk suatu usaha tertentu, dimana masing-masing pihak memberikan kontribusi dana dengan ketentuan bahwa keuntungan dan risiko akan ditanggung bersama sesuai dengan kesepakatan.

Menurut Naf'an (2014:100), akad musyarakah dibedakan menjadi dua, yaitu:

1. Musyarakah pemilikan Musyarakah pemilikan tercipta karena warisan, wasiat, atau kondisi lainnya yang mengakibatkan pemilikan satu aset oleh dua orang atau lebih.

2. Musyarakah akad (kontrak)

Musyarakah akad tercipta dengan cara kesepakatan dimana dua orang atau lebih setuju bahwa setiap orang ari mereka memberikan modal musyarakah. Mereka pun sepakat berbagi keuntungan dan kerugian. Musyarakah akad terbagi menjadi beberapa kategori diantaranya: Syirkah al-'Inan, Syirkah Mufawadhah, Syirkah A'maal, Syirkah wujuh, Syirkah alMudharabah/syirkah Qiradh.

\section{Pembiayaan akad musyarakah Mutanaqisah \\ Menurut Nafik dalam bukunya yang berjudul Bursa Efek dan Investasi}


Langi, et al/JurnalEkonomi Syariah Teori dan Terapan Vol. 6 No. 1 Januari 2019: Hal 188-197; MANAJEMEN RISIKO PEMBIAYAAN MUSYARAKAH MUTANAQISAH DI BANK MUAMALAT INDONESIA KC MAS MANSYUR SURABAYA

Syariah(2009:287), mengatakan bahwa musyarakah mutanaqisah sering disebut musyarakah al-milk yaitu kepemilikan bersama dua orang atau lebih atas properti tertentu. Semua orang yang terlibat di dalam syirkah memiliki porsi yang sama. Menurut Fatwa Dewan Syariah Nasional Majelis Ulama Inonesia (DSN-MUI) No. 73/DSN-MUI/XI/2008, tentang musyarakah mutanaqisah, pada bagian pertama ketentuan umum menyebutkan bahwa yang dimaksud dengan musyarakah mutanaqisah adalah musyarakah atau syirkah yang kepemilikan aset (barang) atau modal salah satu pihak (syarik) berkurang disebabkan pembelian secara bertahap oleh pihak lainnya.

Struktur produk berbasis akad musyarakah mutanaqisah dibuat seara multi akad (hybrid) yang selain akad musyarakah terdiri dari atas akad ijarah (leasing), ijarah maqsufah fi zimmah (advance/forward lease), bai al musawamah (penjualan) ataupun akad istisna (manufaktur).

\section{Risiko}

Menurut Karim

(2014:255)

menyatakan, bahwa risiko dalam konteks perbankan merupakan suatu kejadian potensial, baik yang dapat diperkirakan (anticipated) maupun tidak dapat diperkirakan (unanticipated) yang berdampak negatif pada pendapatan maupun permodalan bank. Risiko-risiko tersebut tidak dapat dihindari namun dapat dikelola dan dikendalikan. Risiko merupakan hal yang tidak dapat dipisahkan dari kehidupan manusia. Hal ini disebabkan banyaknya ketidakpastian yang muncul secara alamiah. Islam memandang bahwa risiko merupakan sebuah sunnatullah dalam sebuah bisnis. Manusia hanya dapat memprediksi berdasarkan pengamatannya, termasuk memprediksi kerugian yang mungkin terjadi di masa depan. Dalam usahanya mencari nafkah, manusia dihadapkan pada kondisi yang tidak pasti.

\section{Risiko pada Akad Musyarakah Mutanaqisah}

Setiap pembiayaan akan memiliki masing-masing risiko. Dalam akad musyarakah mutanaqisah juga memiliki risiko diantaranya adalah risiko kepemilikan, risiko regulasi, risiko pasar, dan risiko kredit (pembiayaan) Hosen (2000:9).

a. Risiko kepemilikan

Dalam pembiayaan musyarakah mutanaqisah, status kepemilikan barang masih menjadi milik bersama antara pihak bank syariah dan nasabah. Hal ini merupakan konsekuensi dari pembiayaan musyarakah mutanaqisah, dimana kedua belah pihak ikut menyertakan dananya untuk membeli barang.

Pada saat transfer kepemilikan barang, pihak nasabah dapat menguasai kepemilikan barang sepenuhnya setelah dilakukan pembayaran bagian bank syariah oleh nasabah beserta besaran vang sewa yang disepakati bersama.

b. Risiko regulasi

Praktek musyarakah mutanaqisah 
Langi, et al/JurnalEkonomi Syariah Teori dan Terapan Vol. 6 No. 1 Januari 2019: Hal 188-197;

MANAJEMEN RISIKO PEMBIAYAAN MUSYARAKAH MUTANAQISAH DI BANK MUAMALAT INDONESIA KC MAS MANSYUR SURABAYA

untuk pembiayaan barang terikat dengan peraturan atau regulasi yang berlaku. Salah satu regulasi yang diberlakukan untuk pola musyarakah mutanaqisah adalah masalah pembeban pajak pertambahan nilai (PPN) pada kepemilikan barang.

C. Risiko Pasar

Ketentuan pasar akan menyebabkan terjadinya fluktuasi harga suatu barang. . Dalam sewa dapat berfluktuasi sesuai dengan situasi dan kondisi saat berlangsungnya akad kerjasama tersebut. Sewa yang ditentukan atas obyek barang akan dipengaruhi oleh: 1. Waktu terjadinya kesepakatan, 2. Tempat/ wilayah, 3. Supply dan demand atas barang tersebut.

d. Risiko kredit (Pembiayaan)

Proses pelaksanaan pembiayaan musyarakah mutanaqisah yang dilakukan dengan cara mengangsur setiap bulan akan terkena risiko kredit. Dimana dimungkinkan terjadinya wanprestasi dari pihak nasabah yang tidak mampu menunaikan kewajibannya untuk membayar angsuran setiap bulan berakibat pada kegagalan kontrak yang dapat menjadi penyebab munculnya kerugian pihak bank syariah.

\section{Manajemen Risiko}

Dalam menghadapi berbagai risiko perbankan tersebut, maka perbankan, termasuk perbankan syariah diwajibkan menerapkan manajemen risiko sebagai implementatif dari prinsip kehati-hatian sebagaimana diwajibkan oleh Undang$\begin{array}{llll}\text { Undang Nomor } 7 & \text { Tahun } 1992\end{array}$ sebagaimana telah diubah dengan Undang-Undang Nomor 10 Tahun 1998. Menurut Karim (2014:260) mengatakan, untuk dapat menerapkan proses manajemen risiko, pada tahap awal bank syariah harus secara tepat mengenal dan memahami serta mengidentifikasi seluruh risiko, baik yang sudah (inherent risks) maupun yang mungkin timbul dari suatu bisnis baru bank. Selanjutnya secara berturut-turut, bank syariah perlu melakukan pengukuran, pemantauan dan pengendalian risiko. Proses ini terus berkesinambungan sehingga menjadi sebuah lifecycle.

Proses manajemen risiko merupakan tindakan dari seluruh entitas terkait di dalam perusahaan yang di dalamnya terdapat berbagai tahapan yang saling berkaitan dan berulang untuk saling melengkapi dan menyempurnakan. Proses manajemen risiko berjalan beriringan dengan proses bank Islam itu sendiri dan menyatu dengan seluruh aktivitas bisnis yang dilakukan oleh bank Islam. Tujuan utama dari manajemen risiko sendiri adalah untuk memastikan bahwa seluruh kebijakan risiko dan bisnis bisa diimplementasikan secara konsisten (Wahyu,dkk, 2013:59). menurut Wahyudi, dkk, 2013:61 alur proses manajemen risiko adalah menentukan konteks, kemudian identifikasi risiko, analisis risiko, evaluasi risiko, perlakuan risiko. 
Langi, et al/JurnalEkonomi Syariah Teori dan Terapan Vol. 6 No. 1 Januari 2019: Hal 188-197; MANAJEMEN RISIKO PEMBIAYAAN MUSYARAKAH MUTANAQISAH DI BANK MUAMALAT INDONESIA KC MAS MANSYUR SURABAYA

III. METODE PENELITIAN

Untuk

mendapatkan

pemahaman yang

mendalam

tentang proses manajemen risiko akad musyarakah mutanaqisah pada Bank Muamalat Indonesia KC Mas Mansyur Surabaya, maka penelitian ini menggunakan pendekatan kualitatif. Sejalan dengan tujuan dan rumusan masalah penelitian, metode yang digunakan dalam penelitian ini adalah metode studi kasus. Ruang lingkup penelitian terkait dengan rumusan masalah dalam penelitian ini. Bank yang dijadikan subjek penelitian adalah Bank Muamalat Indonesia kantor cabang pembantu Mas Mansyur, yang beralamat di Jl. KH Mas Mansyur 147 Nyamplungan Surabaya. Sumber dan jenis data diperoleh dengan cara sebagai berikut:

a. Data Primer

Data primer yang dijadikan sumber data dalam penelitin ini adalah sebagai berikut: wawancara kepada relation customer, Barch Manager, dan relation remidial yang mengetahui keseluruhan bagaimana proses akad musyarakah mutanaqisah di Bank Muamalat Indonesia KC Mas mansyur Surabaya.

b. Data Sekunder

Data tambahan dalam penelitian ini adalah dokumen tertulis, seperti laporan kegiatan penelitian yang pernah dilakukan yang terkait dengan akad musyarakah mutanaqisah di Bank Muamalat
Indonesia, jurnal, internet, buku, sumber lain yang memiliki keterkaitan dengan penelitian ini.

Pada penelitian ini peneliti menggunakan triangulasi sumber data. Untuk mengetahui bagaimana Bank Muamalat Indonesia KC Mas Mansyur melakukan manaejemen risiko pada akad Musyarakah mutanaqisah, peneliti akan menggunakan teknik pengelolaan data yang di dapat selama penelitian di lapangan. Lebih jauh menurut Miles dan Hubberman dalam Yusuf Muri (2014:407) yaitu:

\section{Reduksi Data}

Reduksi data menunjuk kepada proses pemilihan, pemokusan, penyederhanaan, pemisahan, dan pentransformasian data "mentah" yang terlihat dalam catatan tertulis lapangan (written-up field notes). Peneliti memilih data mana akan diberi kode, mana yang ditarik kelvar, dan pola rangkuman sejumlah potongan atau apa pengembangam ceritanya merupakan pilihan analitis.

2. Data Display (penyajian data)

Kegiatan utama kedua dalam tata alir kegiatan analisis data adalah data display. Display dalam konteks ini adalah kumpulan informasi yang telah tersusun yang membolehkan penarikan kesimpulan dan pengambilan tindakan.

3. Kesimpulan/Verifikasi

Data yang telah disajikan, akan dilakukan penarikan kesimpulan serta 
Langi, et al/JurnalEkonomi Syariah Teori dan Terapan Vol. 6 No. 1 Januari 2019: Hal 188-197; MANAJEMEN RISIKO PEMBIAYAAN MUSYARAKAH MUTANAQISAH DI BANK MUAMALAT INDONESIA KC MAS MANSYUR SURABAYA

verifikasi. Penarikan kesimpulan dilakukan untuk menjawab pertanyaan yang telah dirumuskan dalam rumusan masalah sebelumnya.

\section{HASIL PENELITIAN DAN PEMBAHASAN}

\section{Manajemen Risiko Bank Muamalat Indonesia}

Identifikasi Risiko Pembiayaan MMQ

Identifikasi risiko dimulai dengan melihat data atau dokumen calon nasabah yang dimana data tersebut didapatkan dari $\mathrm{Bl}$ Checking dalam rangka untuk melihat record atau historical payment dimana data tersebut berisi tentang rekaman pembiayaan yang pernah dilakukan calon nasabah. apakah memiliki track record yang baik atau tidak baik dalam pelunasaan pembiayaan. Kemudian dilakukan proses penilaian karakter nasabah yang dapat dilakukan melalui wawancara atau terjun langsung melihat bagaimana karakter calon nasabah, melihat kebenaran dari data nasabah tentang karir nya, pekerjaan, jabatan, gaji. Kemudian dari usia calon nasabah merupakan salah satu identifikasi risiko, karena semakin tua usianya akan semakin mempengaruhi jangka waktu yang akan diberikan juga. Jadi pada proses identifikasi risiko ini, Bank Muamalat Inonesia KC Mas Mansyur Surabaya menerapkan prinsip 5C yakni Character, Capacity, Capital, Condition, Collateral.

Beberapa risiko yang berhasil ditemukan pada pembiayaan musyarakah mutanaqisah, yaitu:

1. Risiko kegagalan nasabah dalam $\begin{array}{ll}\text { melaksanakan } & \text { kewajibannya } \\ \text { terhadap } & \text { pembiaayaan }\end{array}$ musyarakah mutanaqisah.

2. Risiko terjadinya kenaikan atau fluktuasi harga pembiayaan musyarakah mutanaqisah.

3. Risiko terjadinya kesalah pahaman antara bank dan nasabah dalam kepemilikan asset.

\section{Analisis Risiko Pembiayaan MMQ}

Pada tahap Analisis risiko, pihak bank melakukan analisis terhadap beberapa risiko yang teridentifikasi. Seperti pernyataan dari Bu Risma menyatakan:

"kita analisis si apa penyebab dari risiko-risiko itu. Misal kalau risiko gagal bayar ya kita lihat kok bisa nasabahnya itu gagal bayar apa usahanya bangkrut atau di phk. Kalau di risiko pasar kita juga lihat kenapa ada kenaikan harga angsuran, ohhh karena harga dipasaran itu naik, jadi kita melakukan review mengikuti harga pasar. Terus kalau risiko kepemilikan juga analisis kenapa nasabah itu bisa ngerubah rumahnya padahal dijelaskan bahwa bentuk rumah nggak boleh dirubah selama masa akad berlangsung. Dan yang jelas kita ngehitung frekuensi dari risikorisiko tersebut, seberapa sering risiko tersebut terjadi"

Dalam wawancara yang dilakukan peneliti dengan pak galih sebagai relation manager customer financing sebagai berikut:

"Yaa... kita analisis kenapa bisa itu terjadi. Kan kita menerapkan 5c ya character, capacity, capital, condition, collateral. Kalau nasabah gak bisa bayar 
Langi, et al/JurnalEkonomi Syariah Teori dan Terapan Vol. 6 No. 1 Januari 2019: Hal 188-197; MANAJEMEN RISIKO PEMBIAYAAN MUSYARAKAH MUTANAQISAH DI BANK MUAMALAT INDONESIA KC MAS MANSYUR SURABAYA

kita lihat apa alasanya, ternyata kesehatannya sedang menurun dan membutuhkan banyak biaya pengobatan, terus bisa jadi nasabah nya kena PHK, terus juga bisa usaha yang sedang dijalani mengalami penurunan. Kalau masalah review itu kita analisis kenapa nasabah bisa terkejut ketika dilakukan review ternyata pehaman nasabah tentang musyarakah mutanaqisah kurang, nasabah pikir sama kaya murabahah.kita juga lihat dari cabang-cabang lain, dihitung berapa frekuensi dari kejadian tersebut"

Dari hasil wawancara ketiga informan diatas, disimpulkan bahwa pihak Bank Muamalat Indonesia mengukurnya dengan menghitung frekuensi kejadian dari risiko tersebut, dan melihat cabangcabang lain terkait risiko-risiko tersebut, dan dengan mencari tahu dengan menganalisis karakter dari nasabah.

\section{Evaluasi risiko pembiayaan $M M Q$}

Berdasarkan informasi pada hasil penelitin, pihak bank melakukan evaluasi terkait dengan beberapa risiko yang telah teridentifikasi, baik yang sudah pernah terjadi maupun yang belum pernah terjadi. Seperti uraian pada wawancara dengan pak galih sebagai berikut:

"Dari mas mansyur sendiri ngelakuin evaluasi tiap bulannya terkait pembiayaan yang membahas tentang seluruh risiko itu sudah diidentifikasi dan sudah dianalisis penyebab terjadinya risiko, kerugian yang kemungkinan terjadi terhadap risiko tersebut, kemudian pengelolahan agar risiko tersebut nggak keulang lagi dihari berikutnya, dan cara menangani risiko yang terjadi di lapangan, kita pihak bank selalu monitoring dan memantau risiko- risiko itu."

Pada tahap ini evaluasi bisa berupa pemeriksaan biasa atau pengamatan terhadap apa yang sudah ada, baik secara berkala atau secara khusus. Bank Muamalat Indonesia KC Mas Mansyur Surabaya melakukan rapat tiap bulannya untuk memantau terhadap risikorisiko yang ada di Mas Mansyur dan melihat apakah proses-proses pengukuran alasan nasabah, pelaksanaan pengendalian dan pengelolahan sudah benar.

\section{Pengenalian dan Pengelolahan Risiko Pembiayaan $M M Q$}

Pada Bank Muamalat Indonesia KC Mas Mansyur Surabaya melakukan pengendalian dan pengelolahan risiko $M M Q$ dengan dua proses yaitu pengendalian sebelum atau pencegahan dan setelah teridentifikasi risiko tersebut. Dapat dijelaskan sebagai berikut:

\section{Risiko pembiayaan}

Pembiayaan BMI terdiri dari preventive control of credit, adalah pengendalian pembiayaan yang dilakukan dengan tindakan pencegahan sebelum pembiayaan tersebut bermasalah. dan repressive control of credit finance, adalah pengendalian dan pengelolaan pembiayaan yang dilakukan melalui tindakan penyelesaian setelah pembiayaan tersebut bermasalah dengan cara Revitalisasi (Rescheduling, Restructure, Reconditioning 
Langi, et al/JurnalEkonomi Syariah Teori dan Terapan Vol. 6 No. 1 Januari 2019: Hal 188-197; MANAJEMEN RISIKO PEMBIAYAAN MUSYARAKAH MUTANAQISAH DI BANK MUAMALAT INDONESIA KC MAS MANSYUR SURABAYA

dan proses jaminan.

2. Risiko pasar

Pengendalian dan pengelolahan risiko pasar atau penyelesaian risiko pasar. Pada awal akad menjelaskan nasabah bahwa dalam akad musyarakah mutanaqisah dalam pelaksanaannya kedepannya ada yang namanya review dan dapat merubah harga angsuran dan margin yang berasal dari harga pasaran yang berlaku, dimana harga pasar setiap saatnya berfluktuasi. Risiko yang diakibatkan oleh terjadinya fluktuasi harga pembiayaan perumahan yang mengakibatkan harga angsuran dan sewa naik dan berdampak para nasabah terkejut atau lupa akan lupa terhadap review yang dapat menaikan harga tesebut, pihak bank akan menjelaskan kembali bahwa telah dijelaskan di awal bahwa pada akad MMQ akan ada review yang dapat menaik atau turunkan harga barang tersbut. Karena pihak bank mengikuti harga pasar berbeda dengan murabahah yang fix angsurannya sampai akhir akad.

\section{Risiko kepemilikan}

Pengendalian dan pengelolahan risiko kepemilikan yang dilakukan Bank Muamalat Indonesia untuk pengendalian pada saat awal akad dijelaskan bahwa ada ketentuan-ketentuan terkait kepemilikan rumah, dimana kepemilikannya miik bersama antara bank dan nasabah. salah satu ketentuanketentuan tersebut adalah tidak diperbolehkannya mengubah bentuk rumah yang sedang dalam pembiayaan sampai akhir akad atau sampai porsi nasabah telah $100 \%$ full. Mengelolah terjadinya risiko kepemilikan yang berasal dari ketidak tahuan nasabah dalam mengubah bentuk rumah yang dibiayai, mengakibatkan harga rumah tersebut berubah yaitu melakukan koordinasi dengan nasabah atau komunikasi dengan mengunjungi tempat objek jaminan dan atau memantau dengan menelpon tempat atau objek jaminannya.

\section{Pemantauan risiko pembiayaan $M M Q$}

Pada tahap ini pemantauan bisa berupa pemeriksaan biasa atau pengamatan terhadap apa yang sudah ada, baik secara berkala atau secara khusus. Bank Muamalat Indonesia KC Mas Mansyur Surabaya melakukan rapat tiap bulannya untuk memantau terhadap risikorisiko yang ada di Mas Mansyur dan melihat apakah proses-proses pengukuran alasan nasabah, pelaksanaan pengendalian dan pengelolahan sudah benar.

\section{SIMPULAN}

Dari hasil pembahasan di atas, penulis mengambil beberapa kesimpulan mengenai proses manajemen risiko pembiayaan musyarakah mutanaqisah pada Bank Muamalat Indonesia KC Mas Mansyur Surabaya. Kesimpulan tersebut diantaranya adalah:

a. Menentukan konteks__Pihak Bank Muamalat Indonesia KC Mas Mansyur pada tahapan penentuan konteks ini menggunakan buku pedoman pembiayaan sebagai tolak ukur untuk melakukan 
Langi, et al/JurnalEkonomi Syariah Teori dan Terapan Vol. 6 No. 1 Januari 2019: Hal 188-197; MANAJEMEN RISIKO PEMBIAYAAN MUSYARAKAH MUTANAQISAH DI BANK MUAMALAT INDONESIA KC MAS MANSYUR SURABAYA

pembiayaan dan manajemen risiko. Jadi semuaa kegiatan mulai dari tahap awal pembiayaan sampai akhir ada didalam buku pedoman tersebut.

b. Mengidentifikasi risiko__Pihak Bank Muamalat Indonesia KC Mas Mansyur pada tahapan identifikasi risiko, risiko yang ditemukan oleh pihak bank adalah sebagai berikut: Risiko kegagalan nasabah dalam melaksanakan kewajibannya terhadap pembiayaan musyarakah mutanaqisah, Risiko terjadinya kenaikan atau fluktuasi harga pembiayaan musyarakah mutanaqisah, Risiko terjadinya kesalah pahaman antara bank dan nasabah dalam kepemilikan asset.

c. Analisis Risiko_Pihak Bank Muamalat Indonesia KC Mas Mansyur pada tahapan menganalisis risiko dengan melakukan perhitungan risiko, frekuensi kejadian, menganalisis pihak nasabah, dan menganalisis kerugian dengan melihat kerugian di cabang lain.

d. Pengendalian dan Pengelolahan Risiko_Mengendalikan dan mengelola risiko yang ada pada pembiayaan musyarakah mutanaqisah dengan cara-cara yang telah ditentukan oleh Bank Muamalat Indonesia KC Mas Mansyur diantaranya untuk risiko pembiayaan dengan proses Revitalisasi (3R), dan melakukan proses jaminan. Sedangkan untuk risiko terjadinya perubahan harga dengan melakukan memberitahu nasabah bahwa sudah dijelaskan di awal akad bahwa pembiayaan $M M Q$ akan dilakukan review harga yang dapat mengakibatkan harga tersebut naik atau turun. Sedangkan untuk risiko yang terjadi akibat kesalahan nasabah dalam kepemilikan akan melakukan Melakukan koordinasi dengan nasabah atau komunikasi dengan mengunjungi tempat objek jaminan dan atau memantau dengan menelpon tempat atau objek jaminannya.

e. Evaluasi Risiko

Pihak Bank Muamalat Indonesia KC Mas Mansyur pada tahapan evaluasi yaitu dengan Melakukan rapat tiap bulannya untuk memantau terhadap risiko- risiko yang ada di Mas Mansyur dan melihat apakah proses-proses pengukuran alasan nasabah, pelaksanaan pengendalian dan pengelolahan sudah benar.

\section{DAFTAR PUSTAKA}

Dsnmui.or.id diakses pada 11 september 2017 pukul 21.41

Hosen, M Nadratuzzaman Hosen. 13 November 2017. www.ekonomisyariah.org Karim A, Adiwarman. 2014. Bank Islam: analisis fiqih dan kevangan. Jakarta. PT. Raja Grafindo Persada. Nafik HR, Muhammad, 2009. Bursa Efek dan Investasi syariah. jakarta: PT. Serambi Ilmu Semesta 
Langi, et al/JurnalEkonomi Syariah Teori dan Terapan Vol. 6 No. 1 Januari 2019: Hal 188-197;

MANAJEMEN RISIKO PEMBIAYAAN MUSYARAKAH MUTANAQISAH DI BANK MUAMALAT INDONESIA KC MAS MANSYUR SURABAYA

Naf'an,2014. Pembiayaan Musyarakah

dan Mudharabahi. Yogyakarta:

Graha IImu

Standar Produk Perbankan Syariah

Musyarakah dan Musyarakah

Mutanaqisah, 2016.

Sugiyono, Prof. Dr. 2012. Metode Penelitian

Kuantitatif, kualitatif, dan R\&D.

Bandung: Alfabeta.

Wahyudi, Imam, et al. 2013. Manajemen

Risiko Bank Islam. Jakarta: Salemba

Empat.Yin, Robert K. 2009. Studi

kasus: desain\& Metode. Jakarta:

Prenada media. 